DOI: 10.14526/2070-4798-2019-14-4-80-85

\title{
Independent physical culture activity of students in the structure of physical upbringing at a higher educational establishment
}

\author{
Marina L. Listkova* \\ Omsk State Pedagogical University \\ Omsk, Russia \\ ORCID:0ooo-0oo2-7481-6059, Lest58@mail.ru*
}

\begin{abstract}
Independent physical culture activity of students, in our opinion, is the most effective form of motor activity deficiency prevention. Materials. The article is about the problems of physical upbringing effectiveness improvement at a higher educational establishment on the basis of independent physical culture activity organization among students. Research methods. General theoretical: information retrieval, scientific-methodical, psychological-pedagogical, sociological, encyclopedic and valeological sources analysis and summarizing; pedagogical experience summarizing. Results. Independents physical culture activity among students are the most optimal form for motor activity deficiency prevention during the periods of physical culture lessons absence. It is especially urgent for students, who have insufficient level of health, physical fitness, who don't have knowledge, skills in the sphere of physical culture and sport [1]. Conclusion. In order to increase the effectiveness of physical upbringing among students independent physical culture activity organization and introduction unit (concerning everyday activity of students, whose physical activity is restricted only by academic lessons) should be included into the program of physical upbringing departments.
\end{abstract}

Keywords: students, motor activity, physical training, students' independent physical culture activity.

For citation: Marina L. Listkova*. Independent physical culture lessons of students in the structure of physical upbringing at a higher educational establishment. Russian Journal of Physical Education and Sport. 2019; 14(4): 68-72. DOI: 10.14526/2070-4798-2019-14-4-80-85.

\section{INTRODUCTION}

The aim of target-oriented program "Physical culture and sport development program in the Russian Federation for the period 2016-2020" is "the conditions creation, which provide the opportunity for citizen to go in for physical culture and sport systematically and increase the effectiveness of training athletes in professional sport" [2, p. 1]. The main priority of social and economic politics of the federal target-oriented program is healthy way of life standards popularization, people involvement into systematic physical culture and sport lessons, health state of population improvement.

Success of Russian athletes at the International arena proves viability of a strong nation. The program says that the number of students, who systematically go in for physical culture and sport, should be increased till $80 \%$ from their general amount.

The effectiveness of federal target-oriented program social-economic realization is estimated owing to the qualitative index "economic effect from population involvement into physical culture and sport activity". It is demonstrated in the decrease of days, when people have temporary disability. This index increase proves positive results of the program realization.

In order to provide methodical development of physical culture and sports activity organization the program provides scientific research works, experimental works of civil function realization [2; $3]$. The set aim realization is possible in terms of scientific- experimental base development, on the basis of which we will form the conditions, necessary for qualitative education realization in the sphere of physical culture.

\section{MATERIALS AND METHODS}

General theoretical: information retrieval, scientific-methodical, psychological-pedagogical, sociological, encyclopedic and valeological sources analysis and summarizing; pedagogical experience summarizing. 


\section{RESULTS AND DISCUSSION}

In terms of transformations in Russia within last ten years, there appears the necessity to reconsider seriously the roles of physical culture for the whole population of the country.

Quick tempo of life nowadays leads to the situation, when students have to spend a lot of time for professional objectives solution. At the same time, they experience great informational and emotional loads. Physical activity in this situation fades into the background. Very often a student forgets about the importance of a rational labor and rest combination. A wide use of computer technologies for work, education and leisure leads to motor activity decrease and the problems appearance with locomotor apparatus [4].

Reforms of higher education are connected with the system modernization in general, however, physical upbringing process is not paid attention to.

Students' physical fitness, corrected in terms of the increased educational load education, is an important part of the educational program mastering quality, as it provides working capacity support of a young organism [5; 6]. However, the existing situation not always proved in reality. "According to the statistics of Russian State Statistics Committee within 2002-2009 more than 70\% of students had health state problems, $80 \%$ of students had distinct hypodynamia, 40\% had vertebra diseases" [7, p. 3] Prevalance of diseases, connected with functional disorders of spine among young people, proves lack of motor activity. It is conditioned by the absence of special physical training programs, realized at higher educational establishments of the country [7].

According to the existing results, in Belgorod State University $10,5 \%$ of first-year students in 2005-2006 were included into a special medical group; in 2006-2007 13,6\% of first-year students; in 2007-2008 - 25,4\% of first-year students; in 2008$200932,4 \%$ of first-year students. Nowadays more and more students belong to a special medical group [8].

Physical culture at a higher educational establishment is the discipline and an important basic component of students' general culture formation. High school development in modern conditions is accompanied by further students' labor intensification, the increasing diversity of information flow, wide use of technical means and computer technologies. In order to support a high level of working capacity, creative productive efficiency of students it is necessary to pay constant attention to own health, motivation development for physical culture activity.

Physical upbringing potential of educational process has great opportunities, which provide physical qualities and professional skills development by means of physical training.

Students' adaptation to professional activity during their education at a higher educational establishment mainly depends on the used physical culture means and would be considered successful in case of high level of students' professional, physical and personal qualities development. They are necessary for effective professional activity [9].

Federal state educational standard of higher education for Bachelor's program, specialty 44.03.01. "The volume of Bachelor's program is 240 credit units (further c.u.) regardless of the education form, used educational technologies, Bachelor's program realization using net form, Bachelor's program realization according to an individual curriculum..." [10, p.2]. However, the claimed norm is not able to provide students' educational level increase in the sphere of physical culture, which together with low independent motor activity leads to students' life quality decrease. During physical upbringing of students we should introduce additional physical culture activity. Integration into the life of students different forms of sports, physical-health improving activity would help to compensate their insufficient physical activity [11].

However, one of such forms of activity is a form of sections. Activity at sections fully provides motor activity deficiency compensation. The amount of lessons increase (from 2 to 3 and more times a week) helps to achieve necessary degree of the training and health-improving effect.

Elective courses and sections during extracurricular activity help to compensate motor activity deficiency. Different additional sportshealth-improving training complexes introduction into the basic system of physical upbringing 
improves the process of physical development, health level, students' physical fitness, helps to support the organism, which leads to working capacity increase regardless of academic lessons.

In our opinion, the range of sections increase (health-improving, sports orientation) at a higher educational establishment wouldn't give the desired result in motor regimen increase for the most part of students. As a rule, one sports section can be attended by 15-25 students and the lessons are held only as extracurricular activity, which restricts throughflow capacity of sports and health-improving sections. Nowadays it is impossible to provide a higher educational establishment with necessary amount of sections because of insufficient material-technical opportunities of higher educational establishments.

That is why additional sections provision at a higher educational establishment is not a prospective direction in the question of mass character development, regardless of their effectiveness for students' motor activity increase, physical and health state improvement.

Going in for sections of health-improving character out of higher educational establishment, sports gyms, swimming pools is not always available for most students because of high price for the presented services.

In our opinion, only students, who have sports experience and a corresponding level of physical fitness, sports categories higher than the first one can go in for sports sections out of a higher educational establishment.

Thus, regardless of evident advantages of sports-health-improving sections in the sphere of physical training, health-improving technologies, nowadays their organizational abilities don't provide the needs of students for mass physical culture activity.

Other opportunities can provide students' independent physical culture activity, which, in our opinion, is able to compensate presented by us disadvantages of educational and sectional activity. This activity organization provides the variety of the means, time of its organization, helps to use an individual approach to solve physical upbringing objectives.

In our opinion, an important factor, which influences physical fitness of students at a higher educational establishment, is presence of exams, holidays, systematic practical activity of different character. It disturbs physical upbringing academic activity [12]. For example, at a pedagogical higher educational establishment there are psychologicalpedagogical, educational, productive, diagnostic, introductive, scientific-research, museum practical activities. One academic year can include two or more kinds of practical activity. More often practical activity is organized during the second part of the academic year. The duration of one practical activity is from 7 to 14 days, in some cases more than 20 days. In case of 7-days practice the gap between physical culture lessons can achieve 11-12 days.

Induced pause in educational physical upbringing process because of practical activity, as a rule, is compensated by lessons transfer to further academic years.

The situation becomes worse, as lessons not always can be held twice a week among the students of the $1^{\text {st }}$ and the $2^{\text {nd }}$ course. Their intensity can be different during the whole academic year. Physical culture lessons schedule for all courses at each academic year can change the interval of their organization, which creates the problem of students' gradual physical fitness control during the academic year.

The interval between physical culture lessons in a yearly cycle of teaching can be the following:

- in January and at the beginning of February- more than 25 days because of winter end-of-semester exams and holidays;

- in February-June- 11-20 days and more during at least one practical activity.

Moreover, curriculum provides several practical activities after educational activity, which creates additional obstacle for the activity at sports sections. This situation is conditioned by thenecessity to optimize education program. It is directed toward more qualitative professional training of students, the demands increase claimed on educational process of the future specialist training. Finally, it becomes impossible to observe the main principles of physical upbringing: systematic character and continuity of physical culture activity. We think that the mentioned contradiction is conditioned by 
insufficient degree of technologies development of physical upbringing organization, the opportunities of its forms study, their adaptation level to changing demands of programs development at a higher educational establishment. The opportunities of students' independent physical culture activity are not studied enough. Its reserve, in our opinion, provides the opportunity to get rid of defined by us drawbacks.

In our opinion, the organization and content of independent physical culture activities plays an important role in their success.

It is also important to study the questions of students' independent physical culture activities, as a pedagogical; higher educational establishment is characterized by the specialties, the students of which after the lessons additionally improve their professional competence at a higher educational establishment from 3 to 7 times a week (musical and art departments). It restricts the opportunity to attend sports and health-improving sections among the students of such specialties and makes the question of independent physical culture activity organization extremely urgent [12].

\section{CONCLUSION}

Independent physical culture activities can be held in any conditions and during convenient time period for the student, can be regulated by a teacher individually for each student.

We think that a teacher's mindset for the task fulfillment activates student's initiative, selfobservation, own activity analysis. In terms of independent physical culture activity students can ask for methodical help at physical upbringing department. It is provided by the main items of the federal state educational standard of the $3^{\text {rd }}$ generation, which prescribes a teacher to for students':

- ability to use axiological potential of physical culture for the system of movements formation form the positions of the main directions of the motor activity management theory, students' interest development in regular physical exercises and sport;

- readiness to realize all kinds of pedagogical control over the state of an organism during physical culture-sports activities organization using instrumental methodologies [13].

\section{REFERENCES}

1. Marina L. Listkova. Programmethodical support of physical culture independent activities among students of higher educational establishments. Pedagogiko-psihologicheskie I medico-biologicheskie problemy fizicheskoj kul'tury I sporta $=$ Russian Journal of Physical Education and Sport. 2019; 14(1): 168-175. DOI 10.14526/20704798-2019-14-168-175 (In Russ., In Engl.)

2. Federal target-oriented program "Physical culture and sport development program in the Russian Federation for the period 2016-2020". Government of the Russian Federation. 2017.

3. Resolution of the Government of the Russian Federation, January, 2, 2018 "On federal target-oriented program "Physical culture and sport development program in the Russian Federation for the period 2016-2020".

4. Trofimova O.V. Physical upbringing development among female students at a higher educational establishment on the basis of thorough study of fitness-aerobics. Candidate's thesis. Cheboksary. 2010: 194.

5. Zabelina L. N. Differentiated methodology of physical qualities development among female students of technical higher educational estbalishment taking into account their individual characteristics. Candidate's thesis. Tula, 2011: 164 .

6. Nebotova I. I. Physical upbringing of students in terms of educational load increase, determined by different level non-profile educational programs integration. Candidate's thesis Krasnodar. 2013: 185 .

7. Rukavishnikova S. K. Pilates means use for spine functional disorders correction among female students of higher educational establishments. Candidate's thesis. SaintPetersburg. 2011: 21.

8. Kopeykina E. N. Physical upbringing process organization among female students with respiratory system disorders. Candidate's thesis. Belgorod. 2010: 132.

9. Bolotin A. E., Tokareva A.V., Puls A.A. Organizational-pedagogical conditions, which are 
necessary for specialists adaptation in defense and extreme situations to professional activity during studying at a higher educational establishment. Uchenye zapiski universiteta imeni P.F. Lesgafta. 2013; 10: 23-28 (In Russ.).

10. Federal state educational standard of higher education (Bachelor's program), specialty 44.03.01 Pedagogical education- appendix. Ministry of Education and Science of the Russian Federation 04.12.2015. №1426.

11. Guseva N. L. Students' motor activity optimization using different forms of physical culture and sports activity. Teoriya I praktika fizicheskoj kul'tury = Theory and practice of physical culture. 2007; 3: 7-9 (In Russ., In Engl.).

12. Listkova M. L. The content of independent physical culture activity substantiation among female students of pedagogical higher educational establishment. Omskij nauchnyj vestnik. 2014; 2: 200-204.
13. Fox B., Fox A. Prosnites!' Vy zhivy! Recept doktora mediciny [Wake up! You are alive! Recipe of Doctor of medicine]. Saint-Petersburg: Dilya, 2007: 256 (In Russ.).

14. Biddle S.J.H., Brehm W., Verheijden M., Hopman-Rock M. Population physical activity behavior change: A review for the European College of Sport Science. European Journal of Sport Science. 2012; 12(4): 367-383. DOI: 10.1080/17461391.2011.635700.

15. Fromel K., Mitas J., Kerr J. The associations between active lifestyle, the size of community and SES of the adult population in the Czech Republic. Health and Place. 2009; 15(2): 447-454. DOI: 10.1016/j.healthplace.2008.08.003

16. Hallal P.C., Andersen L.B., Bull F.C., Guthold R., Haskell W., Ekelund U. Global physical activity levels: Surveillance progress, pitfalls, and prospects. The Lancet. 2012; 380(9838): 247-257. DOI: 10.1016/So140-6736(12)60646-1.

Submitted: 12.11.2019

Author's information:

Marina L. Listkova - Senior Lecturer, Omsk State Pedagogical University, 644099, Russia, Omsk, Naberezhnaya Tukhachevskogo, House 14, e-mail:Lest58@mail.ru 